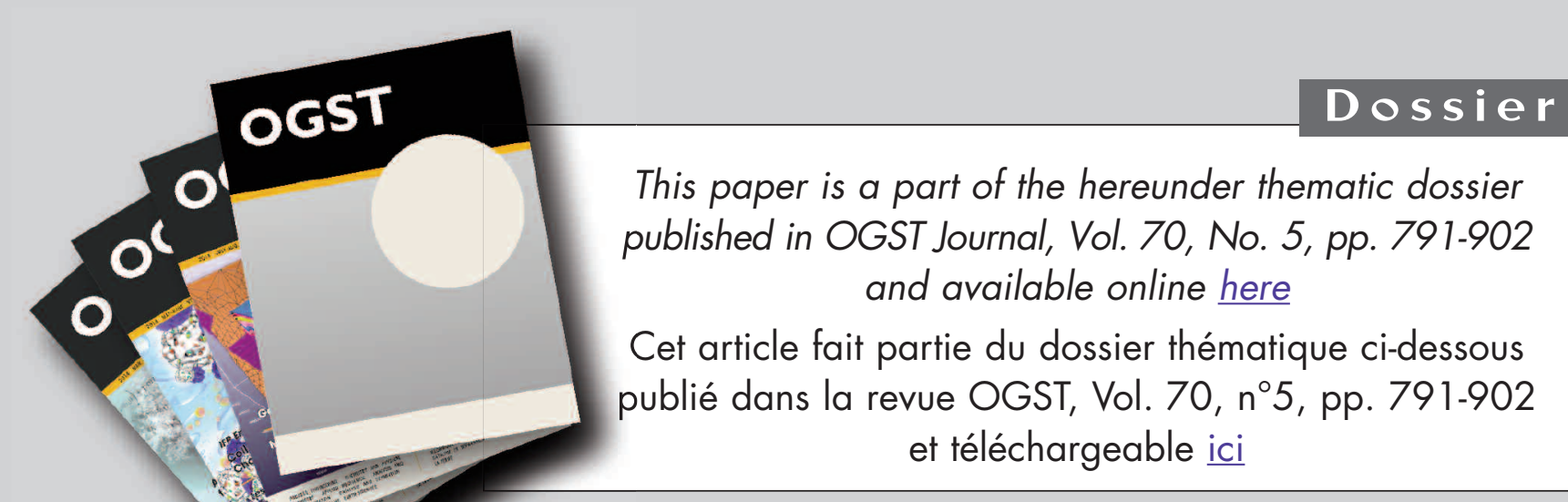

DOSSIER Edited by/Sous la direction de : D. Uzio

IFP Energies nouvelles International Conference / Les Rencontres Scientifiques d'IFP Energies nouvelles

$$
\begin{gathered}
\text { PHOTO4E - Photocatalysis for energy } \\
\text { PHOTO4E - Photocatalyse pour l'énergie }
\end{gathered}
$$

Oil \& Gas Science and Technology - Rev. IFP Energies nouvelles, Vol. 70 (2015), No. 5, pp. 791-902

Copyright (C) 2015, IFP Energies nouvelles

$791>$ Editorial

M. Fontecave, A. Fécant and D. Uzio

$799>$ Solar Production of Fuels from Water and $\mathrm{CO}_{2}$ : Perspectives and Opportunities for a Sustainable Use of Renewable Energy

Production solaire de carburants à partir de l'eau et de $\mathrm{CO}_{2}$ : perspectives et opportunités pour une utilisation durable de l'énergie renouvelable

R. Passalacqua, G. Centi and S. Perathoner

817 > Effect of Post-Synthesis Treatments on the Properties of ZnS Nanoparticles: An Experimental and Computational Study

Effet des traitements après-synthèse sur les propriétés de nanoparticules de ZnS : une étude expérimentale et computationnelle

E. Balantseva, B. Camino, A.M. Ferrari and G. Berlier

831 > Comparative Study on The Photocatalytic Hydrogen Production from Methanol over $\mathrm{Cu}_{-}, \mathrm{Pd}$-, Co- and Au-Loaded TiO

Étude comparative de production d'hydrogène par photocatalyse à partir de méthanol et à l'aide de différentes phases actives ( $\mathrm{Cu}, \mathrm{Pd}, \mathrm{Co}$ et Au) supportées sur TiO

P.P.C. Udani and M. Rønning

841 > Photocatalytic Conversion of Carbon Dioxide Using Zn-Cu-Ga Layered Double Hydroxides Assembled with Cu Phthalocyanine: Cu in Contact with Gaseous Reactant is Needed for Methanol Generation

Conversion photocatalytique du dioxyde de carbone par des hydroxydes doubles lamellaires de Zn-Cu-Ga promus par la phtalocyanine de Cu : nécessité du contact entre le Cu et le réactif gazeux pour la synthèse du méthanol

S. Kawamura, N. Ahmed, G. Carja and Y. Izumi
$853>$ Recyclable PhotoFuel Cell for Use of Acidic Water as a Medium Cellule photocombustible recyclable pour I'utilisation d'eau acide en tant que milieu

Y. Ogura, M. Yoshiba, and Y. Izumi

$863>$ Solar Hydrogen Reaching Maturity L'hydrogène solaire arrive à maturité

J. Rongé, T. Bosserez, L. Huguenin, M. Dumortier, S. Haussener and J.A. Martens

877 > Design of Compact Photoelectrochemical Cells for Water Splititing Conception de cellules photoélectrochimiques compactes pour la décomposition de l'eau

T. Bosserez, J. Rongé, J. van Humbeeck, S. Haussener and J. Martens

891 > Simultaneous Production of $\mathrm{CH}_{4}$ and $\mathrm{H}_{2}$ from Photocatalytic Reforming of Glucose Aqueous Solution on Sulfated Pd-TiO, Catalysts Production simultanée de $\mathrm{CH}_{4}$ et $\mathrm{H}_{2}$ par réformage photocatalytique d'une solution aqueuse de glucose sur un catalyseur Pd-TiO, sulfaté V. Vaiano, G. lervolino, G. Sarno, D. Sannino, L. Rizzo, J.J. Murcia Mesa, M.C. Hidalgo and J.A. Navío 


\title{
Design of Compact Photoelectrochemical Cells for Water Splitting
}

\author{
Tom Bosserez ${ }^{1 *}$, Jan Rongé ${ }^{1}$, Jan van Humbeeck², Sophia Haussener ${ }^{3}$ \\ and Johan Martens ${ }^{1}$ \\ ${ }^{1}$ KU Leuven, Centre for Surface Chemistry and Catalysis, Kasteelpark Arenberg 23, \\ Post box 2461, 3001 Leuven - Belgium \\ 2 KU Leuven, Materials Engineering Department (MTM), Kasteelpark Arenberg 44, \\ Post box 2450, 3001 Leuven - Belgium \\ ${ }^{3}$ École Polytechnique Fédérale de Lausanne (EPFL), Laboratory of Renewable Energy Science and Engineering, \\ Station 9, 1015 Lausanne - Switzerland \\ e-mail: tom.bosserez@kuleuven.be - jan.rongé@kuleuven.be-johan.martens@kuleuven.be \\ jan.vanhumbeeck@kuleuven.be - sophia.haussener@epfl.ch \\ * Corresponding author
}

\begin{abstract}
Solar driven water splitting can be achieved by coupling electrolyzers with PhotoVoltaics $(P V)$. Integration of both functions in a compact PhotoElectroChemical (PEC) cell is an attractive option but presents significant scientific challenges. In this work, the design of single-and dualcompartment PEC cells for research purposes is discussed. The fabrication of separator-electrode assemblies is an important aspect, and upscaling of these architectures even to centimeter scale is not trivial. The layout of a new dual-compartment compact PEC cell with in-situ monitoring of $\mathrm{pH}$, temperatures, and oxygen and hydrogen evolution for research purposes is presented. Finally, a prospect of future PEC cells for practical applications is presented.
\end{abstract}

Résumé - Conception de cellules photoélectrochimiques compactes pour la décomposition de l'eau - La décomposition de l'eau en utilisant la lumière du soleil s'effectue par couplage d'un électrolyseur aux cellules PhotoVoltaïques (PV). L'intégration des deux fonctions dans une seule cellule PhotoElectroChimique (PEC) compacte est envisagée, mais présente un très grand défi scientifique. Cet article traite la conception des cellules PEC de recherche avec ou sans compartimentation. L'assemblage de séparateurs et d'électrodes est un aspect important, et la fabrication de ces architectures, même à l'échelle centimétrique et n'est pas évidente. La disposition d'une nouvelle cellule compacte PEC à deux compartiments permettant de contrôler in situ l'évolution du $\mathrm{pH}$, de la température, et les concentrations d'oxygène et d'hydrogène est présentée. Enfin, une perspective de futures cellules PEC pour des applications pratiques est présentée. 


\section{INTRODUCTION}

In a not so distant future, our society will need to be $\mathrm{CO}_{2}$ neutral by limiting dependence on fossil energy sources. Solar energy can cover a substantial share of our energy needs, but the intermittency and diluteness of sunlight must be alleviated through storage in energy-dense commodities (Mathiesen and Lund, 2009). Solar production of hydrogen is such a storage option. Solar hydrogen can be produced using an electrolyzer powered by PhotoVoltaics (PV) and this technology is readily being applied worldwide. PhotoElectroChemical (PEC) cells present an alternative to the PV-electrolyzer combination by integration of photoabsorption and photocatalysis in a single device. Depending on the application, PEC cells have potential advantages over the coupled PV/electrolysis system as they can provide a more compact and integrated design. Additionally, they can be operated at lower current density exhibiting lower overpotentials and higher efficiency, and enable the use of earthabundant, cheap electrode materials instead of expensive platinum metal for the electrolyzer. PV/electrolysis systems, need an additional DC/DC converter and thus three devices in total. Coupling these units causes energy losses. Both technologies have their merits and the reader is referred to literature for a more detailed scientific comparison (Rongé et al., 2014a; Conibeer and Richards, 2007; Jacobsson et al., 2014).

A PEC cell is a device that achieves water splitting and production of a solar commodity or fuel, e.g. hydrogen, with sunlight as the only energy source. The electrode assembly is the heart of the PEC cell. It consists of photoactive materials such as semiconductors or photosensitizers that absorb light and produce charge carriers. These are separated and consumed in redox reactions at the surface of the photocatalyst or the (electro)catalysts attached to the photoactive material. The electrode assembly is submerged in an electrolyte for ion conductivity and the whole is encased within the reactor or cell, which also offers the channeling for providing the educts to the reaction centers and evacuating the products. A PEC cell hereby simultaneously combines light absorption, charge generation and separation, hole, electron, ionic and molecular transport in a single device (Rongé et al., 2014b). Hydrogen produced in PEC cells is a useful fuel as such. It can be compressed or converted downstream together with $\mathrm{CO}$ or $\mathrm{CO}_{2}$ to liquid hydrocarbon fuel.

Steady progress is being made in the development of light absorbers and (photo)electrocatalysts for photoelectrochemical water splitting. These energy materials are conveniently tested in a three-electrode electrochemical setup to assess their water splitting potential. As PEC cells are reaching maturity, effort should be put into exploring the potential of new energy materials in assemblies, and separation of oxygen and hydrogen by separators dividing anode and cathode compartments. Separator-Electrode Assemblies (SEA) are being implemented in research programs (Rongé et al., 2014a). This paper provides an overview of the development of PEC cells for research purposes, denoted as exPEC cells, and presents some ideas on the design of PEC cells for an ultimate practical application.

\section{STATE-OF-THE ART OF EXPERIMENTAL PEC CELLS}

The multitude of physical and (photo-electro)chemical processes in a PEC cell can only be achieved by a combination of different materials. Many configurations of functional assemblies are possible and different terminologies have been proposed (Rongé et al., 2014b; Nielander et al., 2014). After the successful research efforts on photoactive materials, electrocatalysts, and their combinations, the design of assemblies and the development of cells for operating assemblies are the next research challenge. Clever engineering of PEC cells and optimization at the different length scales are essential with respect to overall efficiency and cost.

It is important to make a distinction between wired and wireless electrode assembly configurations (Fig. 1), (Newman, 2013). In a wired configuration, electrical connection between anode and cathode is established by external wires. These connections enable measurement of (photo)currents and potentials using voltmeter,

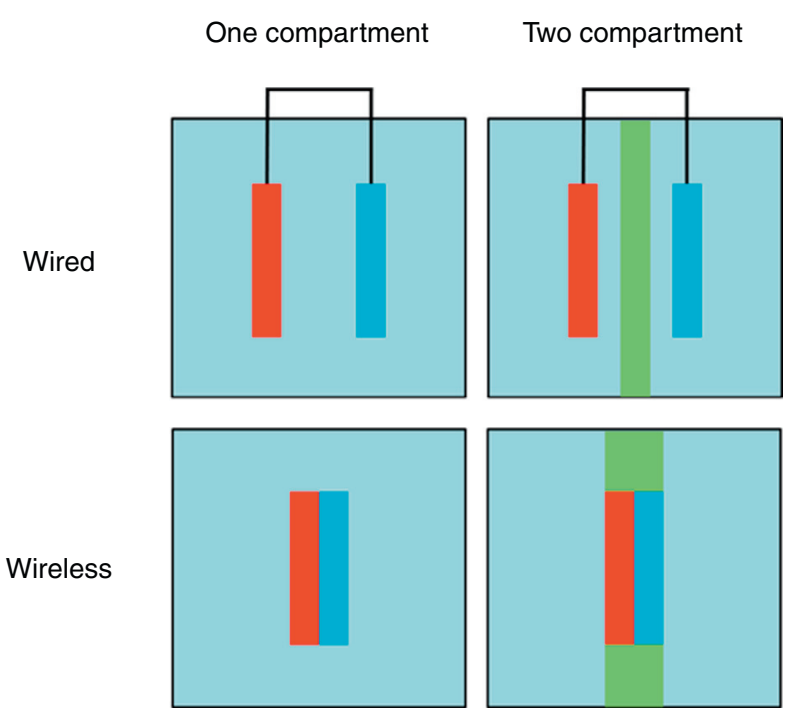

Figure 1

Schematic representation of four possible configurations of electrodes and molecular separators in exPEC cells. Red, blue and green colors represent anode, cathode and separator, respectively. 
ammeter or potentiostat, and detailed (photo)electrochemical characterization of the assembly. The electron pathlength in wired configurations is considerably larger compared to a wireless configuration, possibly taking advantage of the high electrical conductivity of metal wires. At the same time, the electrodes can be placed very closely, reducing the ionic pathlength and enabling the use of low ionic conductivity electrolyte. The opposite holds for the wireless configuration, in which the electron pathlength is minimized while the ionic pathlength is enhanced. A further distinction can be made between wireless and monolithic setup. Wireless means that anode and cathode (and possibly separator) are part of the same physical assembly. Wireless systems are always monolithic. Wired system can be monolithic or not (Rongé et al., 2014b, c).

PEC cells for research purposes denoted exPEC cells can be classified according to compartmentalization. ExPEC cells either have one or two compartments (Fig. 1). To avoid confusion, the term dual compartment will be used here when two compartments are molecularly separated ${ }^{(1)}$ by using an ion exchange separator that allows ionic transport between both compartments but limits the mixing of molecular oxygen and hydrogen. Many different separators can be used such as glass frits, salt bridge or ion exchange membranes. The use of a molecular separator in dual compartment PEC cells has important advantage over singlecompartment exPEC cells. It provides a means for product separation and facilitates analysis of reaction product formation and determination of Faradaic and quantum efficiencies.

\subsection{Single Compartment Experimental PEC Cells}

Single-compartment exPEC cells are most common in water splitting research. Their purpose is to characterize individual (photo)electrodes in a wired, three-electrode configuration (Chen Z. et al., 2011). Here, the working electrode is the study object. The counter electrode typically is a Pt electrode with large surface area to limit its influence on the working electrode. A reference electrode is implemented. Electrochemical techniques for characterizing photoelectrodes include cyclic- or linear voltammetry, Mott-Schottky analysis, impedance spectroscopy, chronoamperometry, etc. (Chen Z. et al., 2013).

Both wired and wireless configurations can be used to characterize an electrode assembly. For wired configurations in single exPEC cells, it is appropriate to use two-electrode measurements. For wireless samples, characterization is limited to product analysis and current cannot be measured. Depending on the sample and the properties to be

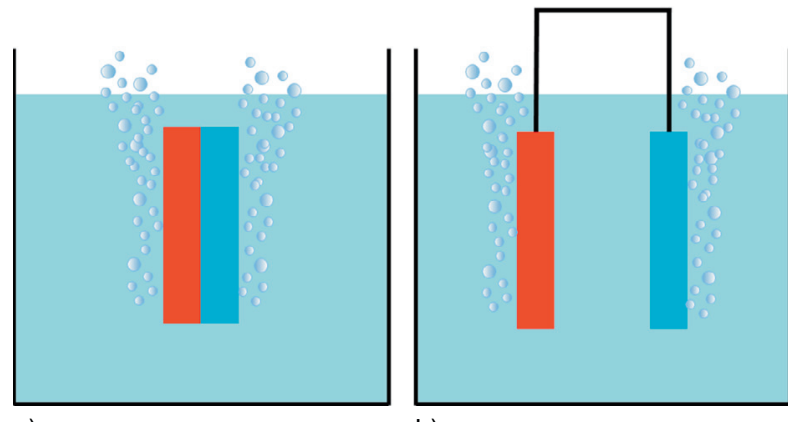

a)

b)

Figure 2

Single compartment exPEC cell with liquid filled container for a) wireless and b) wired electrode configuration.

investigated, many variations in exPEC cell design exist (Minggu et al., 2010).

The most basic exPEC cell is an open beaker filled with a suitable electrolyte (Fig. 2) in which the assembly is submerged and illuminated. This type of setup has been used to demonstrate the working of both wired and wireless cells (Reece et al., 2011; Kelly and Gibson, 2006). Obviously, this design is less convenient for reaction product quantification and it is often used for demonstration purposes only. A more advanced exPEC cell can be sealed from the environment in an air-tight manner to prevent electrolyte leaking and air diffusion into the cell. This is especially important as oxygen at the anode can act as an electron acceptor and its penetration into the cell leads to an overestimation of the oxygen production. Similarly, oxygen at the cathode will recombine with hydrogen to form water and thus underestimate the hydrogen production. In- and outlets can be foreseen to flush the volume with reactive or inert gases to create a controlled environment and enable quantitative product analysis by $e . g$. gas chromatography or mass spectrometry.

The exPEC cell can be made out of any type of glass such as Pyrex ${ }^{\circledR}$ and quartz for visible and UV-light illumination, respectively. However, depending on design, manufacturing these types of cells is not trivial and the implementation of quartz windows is expensive. Chemically inert polymer materials such as Teflon ${ }^{\circledR}$ or PolyEther Ether Ketone (PEEK) are often used as support materials. Insertion of smaller quartz or glass windows can be achieved by sealing with epoxy resin, although generally the use of O-rings is more convenient. ExPEC cells are commercially not available and researchers often design their own exPEC cells. Researchers design their own exPEC cells. Examples are the so called 'Cappuccino' cell designed at EPFL (Fig. 3a), (Lopes et al., 2010), Lausanne, and the exPEC cell designed at TU Delft (van de Krol and Grätzel, 2012). 


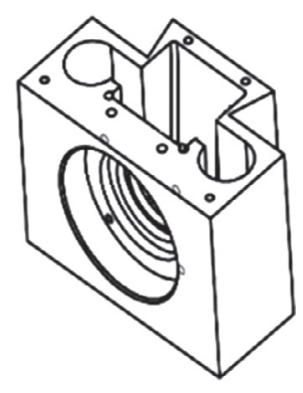

a)

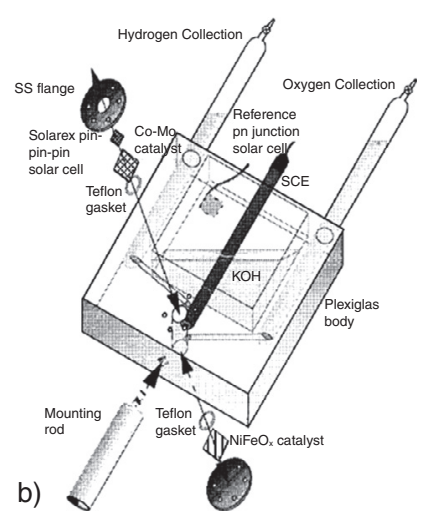

Figure 3

a) ${ }^{(2)}$ Example of the Cappuccino cell designed at EPFL, Switerland, (Lopes et al., 2010); b) ${ }^{(3)}$ exPEC cell reported by Rocheleau et al. (1998).

The latter is an example of a gas tight exPEC cell made out of PEEK. It is handy for characterization of photoelectrodes in a 2- or 3-electrode setup in dark or illuminated conditions. The small characteristic distances between the electrodes minimize ohmic losses. Both the sample and fused silica window can be removed by a threaded insert with an O-ring for gas tightness.

The major drawback of single compartment cells is the mixing of the evolving oxygen and hydrogen gas which entails the complication of recombination reactions. There is a safety aspect if the concentration of hydrogen would reach the explosion limit (Schröder et al., 2004). Hydrogen can be collected separately by proper design of the exPEC cell. In a wired configuration, compartmentalization can be achieved in an $\mathrm{H}$-cell in which a glass frit reduces crossover of bubbles and products recombination. A similar approach was demonstrated by Rocheleau et al. (1998) with a wired configuration (Fig. 3b), (Miller et al., 2003). This experimental setup is suited for characterization of samples working at high current densities as in this case readily detectable amounts of oxygen and hydrogen are produced. Spatial separation of the electrodes, however, leads to larger characteristics distances between the electrodes and correspondingly higher ohmic losses in the electrolyte which can be critical when working at high current densities.

It is obvious that alternative exPEC cell designs present advantages and disadvantages, and the choice will depend on the research focus. While most exPEC cells are suited for screening of (photo)electrodes, they are less convenient for characterizing wired or wireless separator-based electrode assemblies in which anode, cathode and separator are contributing to the overall performance of the system.

\subsection{Dual Compartment Experimental PEC Cells}

Dual compartment exPEC cells have the advantage of producing oxygen and hydrogen gas separately in anode and cathode compartments, respectively. Most designs are based on a Proton Exchange Membrane (PEM) fuel cell, with the water formation reaction occurring in reverse electrochemical direction. In dual compartment exPEC cells two- or fourelectrode measurements are relevant. In a two-electrode setup, as opposed to a three-electrode setup, the counter electrode contributes to the photoelectrochemical characteristics and thus gives a more realistic representation of the complete PEC cell. In a four-electrode setup, two additional reference electrodes are added and their potential difference is measured while applying a current between the work- and counter electrode. This approach gives insight in potential losses between electrodes while discarding the electrodes themselves. It makes it possible to measure the electrolyte resistance (dependent on cell geometry and the resistance of the ionic separator).

The H-cell is a typical dual-compartment cell for wired configurations (Fig. 4), (Hernández-Pagán et al., 2012; Lopes et al., 2014). Anodic and cathodic reactions occur in two separate compartments, connected by a small tube in which the ionic separator is placed with appropriate sealing to prevent leaking. Product gases can be collected vertically while ionic transport occurs in horizontal direction. By implementing $\mathrm{pH}$ electrodes a buildup of $\mathrm{pH}$ gradient across the membrane can be observed (Hernández-Pagán et al., 2012). The phenomenon of $\mathrm{pH}$ gradient buildup occurs even in concentrated buffers. Hernández-Pagán et al. (2012) revealed that the choice of electrolyte, electrolyte volume, and the ionic path length are key parameters for cell performance.

A more advanced type of cell was recently reported by Lopes et al. (2014), (Fig. 4b). The design has additional fused silica windows on both sides of the compact cell. Two compartments can be separated by a Teflon ${ }^{\circledR}$ separator. The illuminated sample surface area can be up to $100 \mathrm{~cm}^{2}$. These properties enable detailed characterization of wired, non-monolithic PEC configurations.

Monolithic electrode assemblies offer opportunities for reducing ionic transport distances (Rongé et al., 2014b). Ichikawa and Doi (1996) reported one of the first investigations of a monolithic assembly. They used a dual-compartment cell to investigate the water splitting reaction in a wired configuration with a thin film anatase anode and 


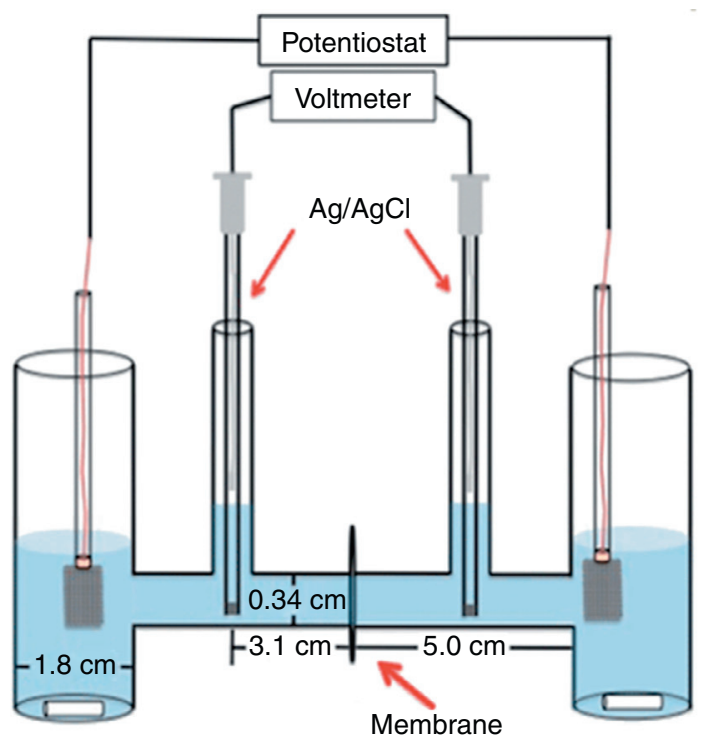

a)

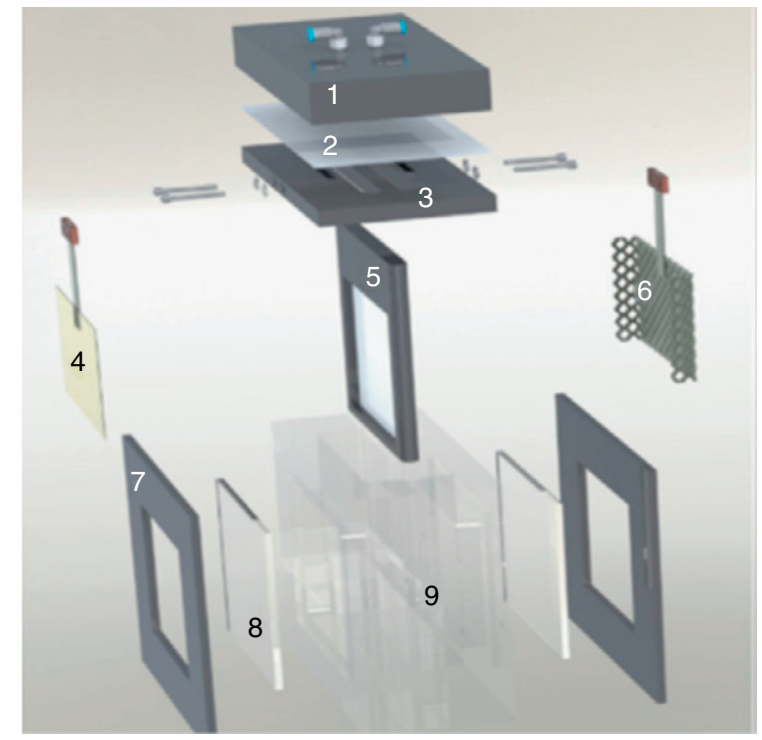

b)

Figure 4

a) ${ }^{(4)}$ Typical H-cell with four-electrode setup (Hernández-Pagán et al., 2012); b) ${ }^{(5)}$ dual compartment exPEC cell designed at LEPABE, Portugal (Lopes et al., 2014).

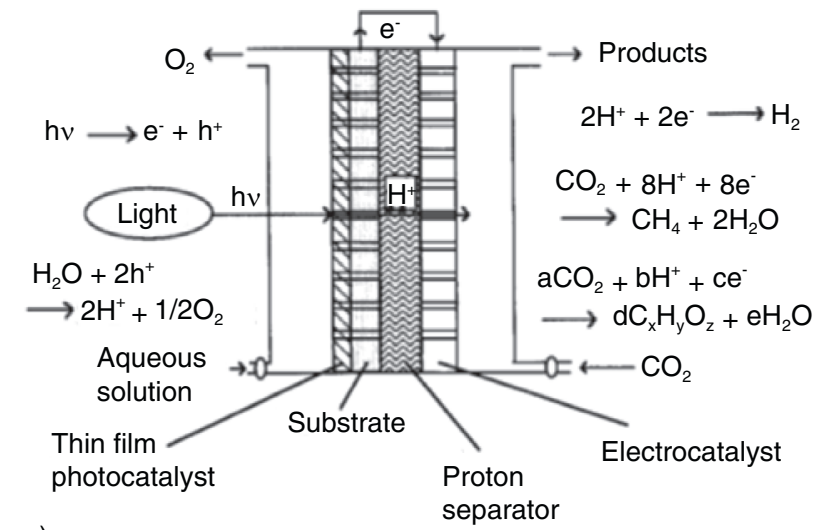

a)

Figure 5

Schemes of dual compartment exPEC cells presented by a $)^{(6)}$ Ichikawa and Doi (1996) and b) ${ }^{(7)}$ Seger and Kamat (2009).

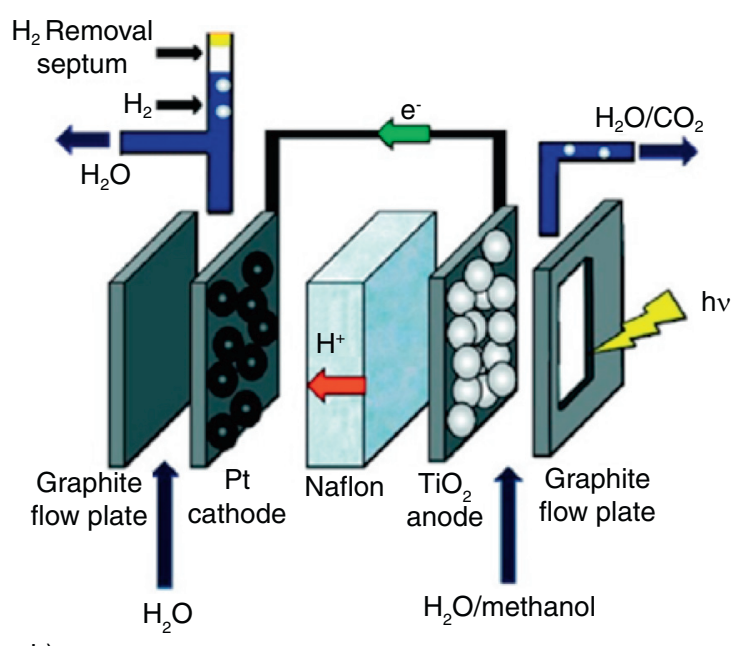

b) a Pt cathode, separated by a Nafion membrane (Fig. 5a) (Ichikawa and Doi, 1996). Later on, similar cells were designed and used by others (Seger and Kamat, 2009; Ampelli et al., 2010; Qian et al., 2010).

Recently, some of us reported a monolithic assembly in a dual compartment exPEC cell that performs solar splitting of water molecules from water vapor collected from ambient air (Fig. 6), (Rongé et al., 2013, 2014c; Schröder et al., 2004). The use of carbon nanotubes coated with a conformal $\mathrm{TiO}_{2}$ coating deposited by Atomic Layer Deposition (ALD) enabled protection of the sample against the detrimental effects of atmospheric oxygen. The same PEC cell was also 


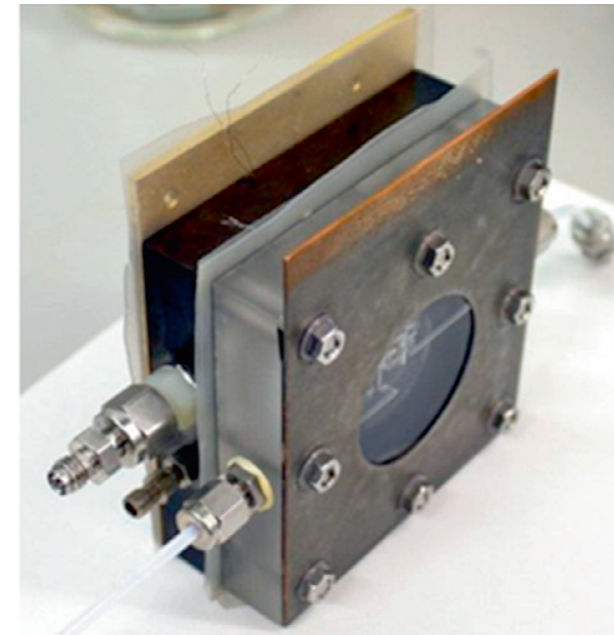

a)

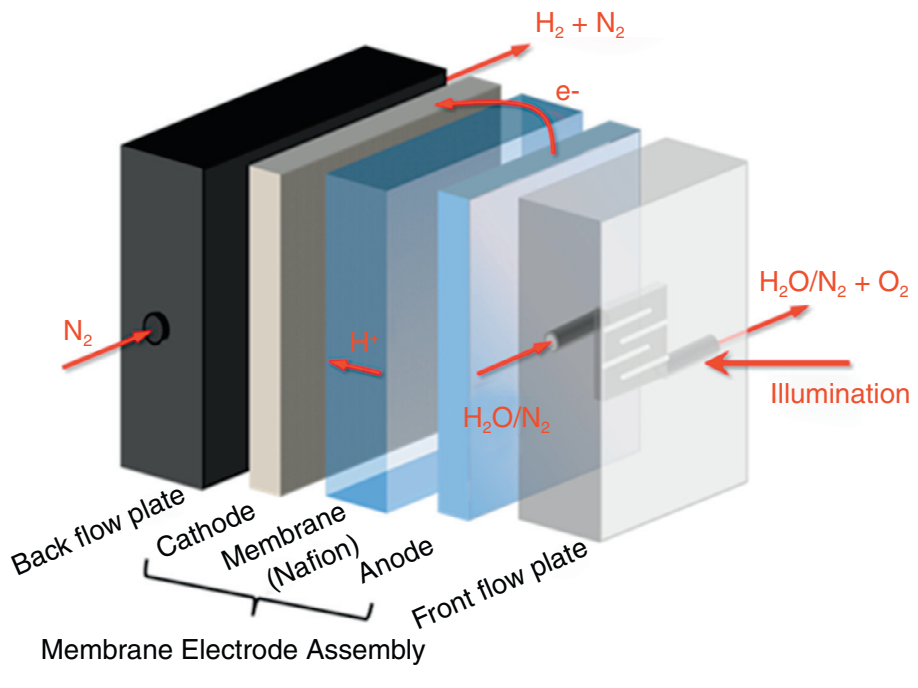

b)

Figure 6

a) Fused silica/graphite dual-compartment exPEC cell from previous work (Schröder et al., 2004) with illumination area of $0.785 \mathrm{~cm}^{2}$; b) schematic representation of the cell and its components ${ }^{(8)}$, (Rongé et al., 2013).

used to investigate scalability of the separator electrode assembly as will be discussed below.

\section{UPSCALING OF MONOLITHIC ASSEMBLIES AND EXPERIMENTAL PEC CELLS}

Increasing surface area of Separator-Electrode Assemblies (SEA) is not obvious. In this section, the upscaling of a recently presented SEA (Rongé et al., 2013) based on carbon nanotubes, carbon paper, Nafion membrane, anatase and platinum electrodes, tested in a dual compartment exPEC cell, is presented.

As mentioned previously, penetration of atmospheric oxygen has detrimental effects (Hagfeldt and Lindström, 1995) and, therefore, it is important for PEC cells to be air tight. Water splitting experiments were performed in a dual compartment exPEC cell with a surface area of $9 \mathrm{~cm}^{2}$, roughly 10 times larger than in previous work (Rongé et al., 2013). This exPEC cell (Fig. 6) is a dual-compartment cell with in- and outlets for reactant feeding and product collection. The cathode compartment was made out of graphite, has serpentine flow channels for optimal fluid flow over the sample surface while providing electrical contact with the electrode. The anode compartment was made entirely out of quartz and is provided with serpentine flow channels. The SEA was mounted in between two silicone gaskets

\footnotetext{
${ }^{8}$ Reproduced from reference Rongé et al. (2013) with permission from The Royal Society of Chemistry.
}

which sealed off the sample from the environment and prevent leaking. Subsequently the mounted SEA was introduced between both compartments and screwed tight by means of 8 insulated screws. UV-illumination of the anode compartment was provided by means of a Xe lamp with IR filter (Oriel 66984, Newport, Irvine, CA) with an incident intensity of $100 \mathrm{~mW} \cdot \mathrm{cm}^{-2}$. In- and outlets allow the exPEC cell to be flushed with either liquid water or water vapor at the anode while the cathode was fed with water saturated $\mathrm{N}_{2}$. The outlets were connected to a mass spectrometer or gas chromatograph for analysis.

Chronoamperometry is convenient for SEA characterization. The photocurrent between anode and cathode upon illumination at short circuit $(0 \mathrm{~V})$ in a two-electrode setup was measured using a potentiostat (Versastat 4, Princeton Applied Research, Oak Ridge, TN with Versastudio electrochemical analysis software). The electrical connection was achieved either by direct contact with the graphite frameworks or if needed by placing $\mathrm{Ti}$ wires and stainless steel wires on the surface of the anode and cathode, respectively. The gas composition at the outlet of the cathode compartment was monitored during illumination with a Quantitative Gas Analyzer (Hiden Analytical, Warrington, UK). The hydrogen signal was corrected for interference by water and the $\mathrm{N}_{2}$ signal was used as internal standard.

Anode and cathode electrodes consisted of carbon fiber paper coated with $\mathrm{TiO}_{2}$ and $\mathrm{Pt}$ on Carbon Black (Pt/CB), respectively. SEA measuring ca. $1 \mathrm{~cm}^{2}$ previously were prepared using a hot press procedure (Rongé et al., 2013, 2014c). 


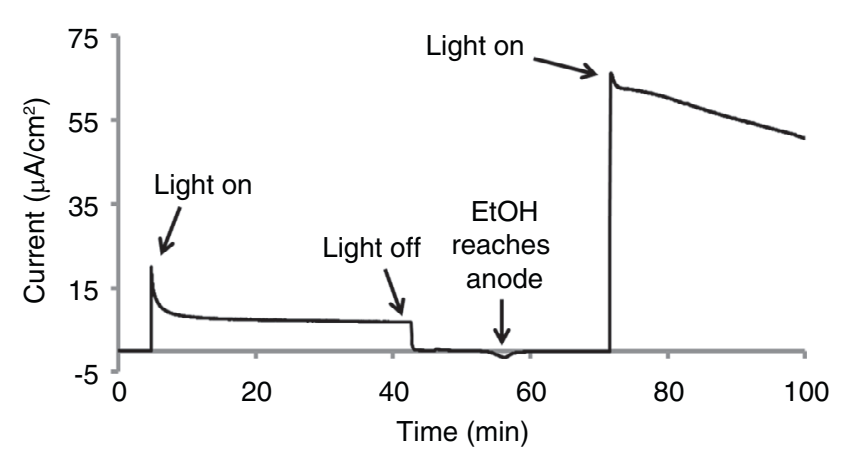

Figure 7

Influence of ethanol addition (after $55 \mathrm{~min}$ ) on observed photocurrent in dual compartment exPEC cell. Ethanol acts as a hole scavenger and is oxidized providing electrons and protons for $\mathrm{H}_{2}$ formation at the cathode.

The Nafion ${ }^{\circledR}$ membrane was sandwiched between the anode and cathode with a few drops of Nafion ${ }^{\circledR}$ suspension, which acted as an adhesive, added on each side. The resulting assembly was then placed between two Teflon ${ }^{\circledR}$ plates and pressed at 50 bar and $130^{\circ} \mathrm{C}$. The SEA was then allowed to cool and was stored at room temperature before use.

Unfortunately, practical problems were encountered during fabrication of $9 \mathrm{~cm}^{2}$ samples. Samples showed cracks in the carbon fiber substrate. These cracks locally interrupted the electrical contact. It was concluded that this cracking was due to a combination of high pressures and temperatures present in the hot press method causing curling of the Nafion membrane after pressing. To overcome the problem a thinner membrane Nafion ${ }^{\circledR}$ XL (27.5 $\mu \mathrm{m}$ thickness) was used. This more flexible variety of Nafion ${ }^{\circledR}$ membrane did not exhibit the curling effect. Additionally, the hot press method was adapted to lower pressures and temperatures.

The Nafion suspension used to prepare SEA contained residual ethanol solvent. EtOH is a known hole scavenger and readily oxidizes on $\mathrm{TiO}_{2}$ surfaces to form acetaldehyde (Araña et al., 2004).

$$
\text { Ethanol } \leftrightarrow \text { Acethaldehyde }+2 e^{-}+2 \mathrm{H}^{+}\left(E^{0}=+0.197 \mathrm{~V}\right)
$$

Thus, the presence of ethanol residues may have dramatic effects on PEC performance, leading to overestimation of the quantum efficiency. To assess the influence of ethanol impurities on PEC performance, the anode was flushed with $\mathrm{N}_{2}$ purged through a water vessel containing $10 \%$ ethanol. Figure 7 shows the photocurrent profile in the presence of EtOH vapor. A short standard measurement was performed prior to the EtOH test to indicate the SEA and exPEC cell were working properly. After introduction of EtOH

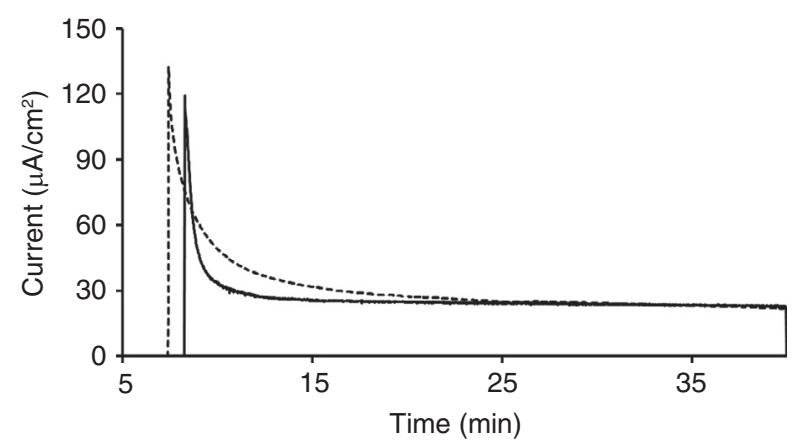

Figure 8

Photocurrent profiles in exPEC cells with illuminated surface area of $1 \mathrm{~cm}^{2}$ (solid line) and $9 \mathrm{~cm}^{2}$ (dotted line).

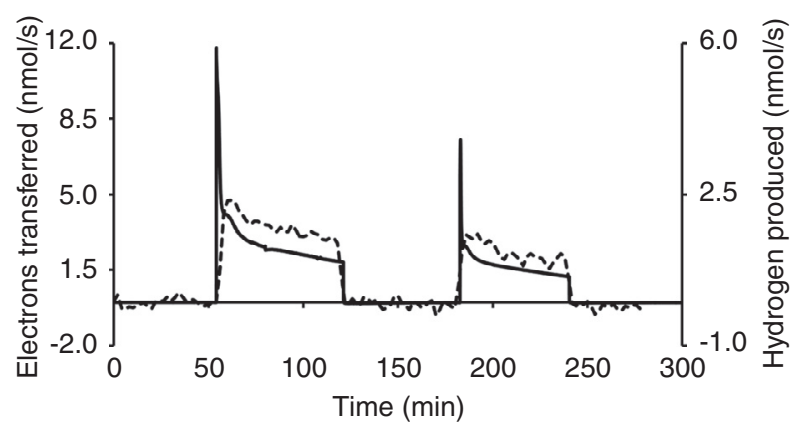

Figure 9

Photocurrent profile (solid) and continuous monitoring of hydrogen production by mass spectrometry (dotted).

to the anode compartment, the photocurrent increased significantly. This current does not contribute to the water splitting reaction. This experience revealed that when working at low currents it is important to make sure no residual organic compounds are present. However, this observation also shows that PEC cells potentially can be used for photoelectrochemical degradation of volatile organic compounds to generate hydrogen.

Reproducible behavior was obtained with the $9 \mathrm{~cm}^{2}$ SEA as shown in Figure 8 . When using $1 \mathrm{~cm}^{2}$ SEA samples the concentration of hydrogen at the cathode was often below the detection limit of the mass spectrometer $\left(1 \times 10^{-11}\right.$ torr $)$ and a continuous measurement was not possible. However, when upscaling, a continuous measurement of the produced hydrogen of $\mathrm{H}_{2}$ formations during an unbiased experiment was possible, as shown in Figure 9.

In the first illumination period, a large anodic overshoot was observed and the production of hydrogen lagged the photocurrent. In the second illumination period, the anodic overshoot was smaller and the hydrogen production was detected faster after illumination. The change of behavior 
a)

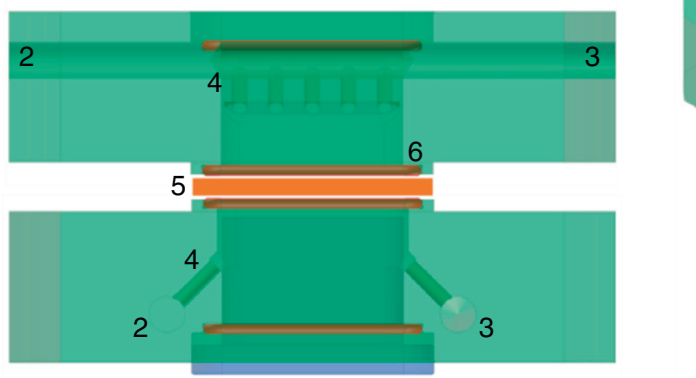

c)

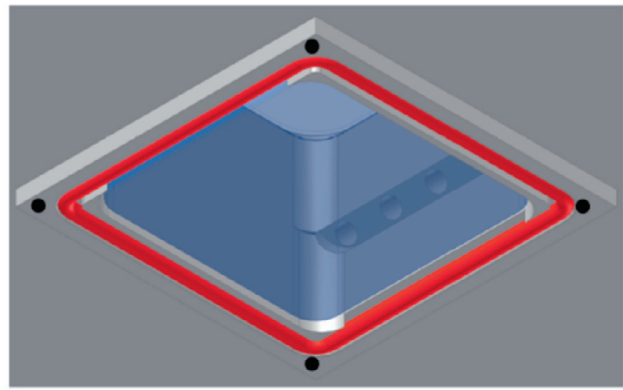

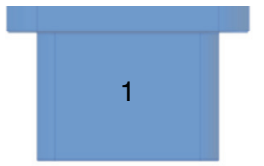

b)
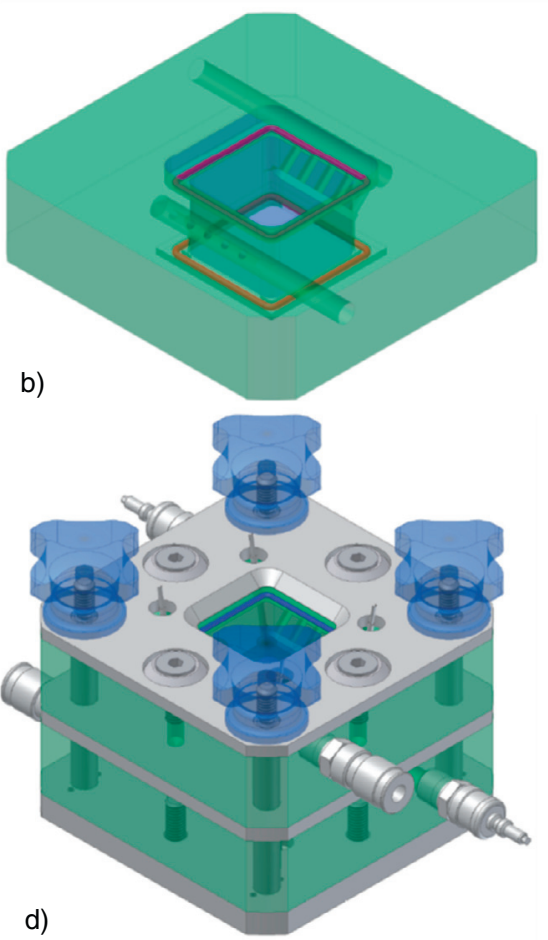

Figure 10

Advanced exPEC cell a) side view of the half cells. 1: Quartz window; 2: Reagent inlet; 3: Product outlet; 4: Inlet distribution or outlet collection; 5: Sample; 6: O-ring. b) Top-side view of the half-cell. c) Bottom-side view of the half-cell. The black dots indicate the spring contacts for electrical contact with the substrate. d) Assembled exPEC cell.

can be explained as follows. A fresh anode has a high concentration of trap states which can be saturated by the sudden production of photoexcited holes. Additionally, the cathode forms hydrides at the Pt surface until saturation only after which the formation of hydrogen molecules was started. In the second illumination period, the surface states at the anode were not yet fully discharged and the Pt surface at the cathode presumably remained hydride saturated. This explains the lower anodic overshoot and the immediate detection of hydrogen production. The lack of a hydrogen overshoot could also be explained by the presence of this charge accumulation at the interface and by the temporal resolution of 2 minutes of the mass spectrometer. Additionally, it is important to mention that the length of the transfer line from cathode outlet to the mass spectrometer needs to be taken into account when designing an exPEC cell to avoid lagging artifacts.

\section{ADVANCED RESEARCH PEC CELLS}

State-of-the-art exPEC cells offers access to a variety of relevant experimental parameters, namely illumination intensity and composition, electrolyte composition (concentration and $\mathrm{pH}$ ), reactant flow rates, and gas composition. There is ample room for refinement and sophistication. Future exPEC cells should enable investigation of the influence of assembly configuration, geometry, temperature, humidity, light incident angle, etc. For this aim, a new dual-compartment exPEC cell with additional functionalities was designed (Fig. 10). The cell is divided in two compartments and consists of two modular half-cells which can be fabricated and optimized separately. Each half-cell is fabricated out of PEEK and is equipped with a quartz window (1) which is pressed into the PEEK half-cell and sealed with a square-shaped polymer sealing. The illuminated surface area is $3 \times 3 \mathrm{~cm}$ extendable by using a larger window.

Each half-cell was manufactured from a solid PEEK block through mechanical milling. The in- and outflow of the cell are conceived for an even flow distribution. At the inlet (2), the flow enters a cylindrical channel after which it is equally divided into 5 smaller cylindrical channels (4). Before reaching the SEA surface, these 5 channels gather into one common channel to redistribute the flow. The flow channel over the sample chamber is approximately $1 \mathrm{~mm}$ 


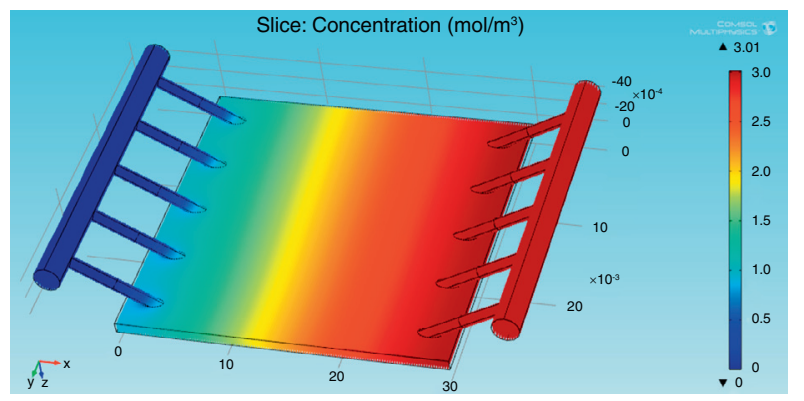

Figure 11

Simulation of the new exPEC cell operation showing the homogeneous buildup of the hydrogen concentration through water splitting in vapor phase.

high to avoid product buildup in dead volumes. The path for reactant and product flow in gas or liquid phase is well defined. The SEA (5) can be mounted in between these two half-cells, each of which seal off the sample from the environment by a square-shaped sealing (6). An electrical contact with the sample is obtained by a connection with four spring contacts located at the four corners of the sample for an equal current or potential distribution across the sample surface area.

Numerical simulations of the 3-D design were performed to evaluate the uniformity of the flow. Width and height of the different channels were varied as well as the flow velocity. A constant hydrogen production activity across the sample surface was assumed. The resulting pressure loss, concentration gradient across the sample surface and velocity profile were calculated using numerical software. The results showed no significant impact of the variables on the observables and thus it was concluded that an equal distribution of the flow over the sample surface could be obtained with this design. Additionally, the model showed that the products can be evacuated from the flow channel without creating a significant concentration gradient over the sample surface (Fig. 11).

By adjusting the height of the quartz window, it is possible to implement sensors close to the sample surface. Sealable insertion holes for the implementation of various sensors is envisioned. Reference electrodes can be inserted for (photo)electrochemical testing in 3- or 4-electrode setup. $\mathrm{pH}$ sensors can be mounted for in situ investigation of $\mathrm{pH}$ gradients. Such $\mathrm{pH}$ gradients over SEA recently have been simulated and experimentally observed (HernándezPagán et al., 2012; Jin et al., 2014). Additionally, $\mathrm{O}_{2}$ - and $\mathrm{H}_{2}$-microsensors fitting in the flow channel can be mounted for time resolved reaction monitoring, close to the active SEA surface. Temperatures can be monitored by insertion of thermocouples or by infrared detection directly on the surface.

\section{DESIGN OF PRACTICAL SMALL TO LARGE SCALE PEC CELLS}

PEC cells can be envisioned at a small scale for domestic applications. A PEC cell with an efficiency of $20 \%$ would need about $50 \mathrm{~m}^{2}$ of surface area to cover the daily energy needs of an average family with a consumption of $20 \mathrm{kWh} \cdot \mathrm{day}^{-1}$. This energy corresponds to a volume of about $3 \mathrm{~m}^{3}$ of hydrogen at atmospheric pressure which can be highly reduced when pressurized. PEC cells can also be employed on a large scale for industrial applications where the produced hydrogen gas should be pressurized to ensure practical transportation. Additionally hydrogen could be coupled to carbon dioxide mitigation for storage as hydrocarbons or used for downstream processes such as ammonia production.

Anyhow, practical PEC cells will differ from exPEC cells in many respects. Commercial PEC cells should have a design that is simple, cost effective, sustainable, safe, and durable. As the scale of PEC-based hydrogen processing increases more technical difficulties concerning both the SEA and the cell assembly will arise. Many designs are possible and have already been investigated by technoeconomic and life cycle analysis (Pinaud et al., 2013; James et al., 2009; Sathre et al., 2014; Zhai et al. 2013). In general, two designs seem feasible for large-scale hydrogen production:

- fixed panel PEC cells,

- concentrator PEC cells.

Systems based on suspended nanoparticles have been proposed as well, but those are in an earlier development state. Storage of hydrogen is still a highly disputed topic within the community of PEC cells, the storage versus downstream transformation will not be considered here.

Both wired and wireless configurations have been proposed for large scale fixed panel PEC cells (Pinaud et al., 2013; James et al., 2009; Sathre et al., 2014; Zhai et al., 2013). In wired design, the importance of correct electrical contacts of the large electrodes should not be overlooked. Although ohmic losses in electrical systems are generally negligible compared to losses due to ionic transport, in practice it is not evident to manufacture effective electrical contacts and they can be quite demanding in the overall cell design. A low resistance ohmic contact is imperative for current collection and is not always straightforward to obtain as it depends on the involved materials ${ }^{(9)}$.

\footnotetext{
${ }^{9}$ The choice of contact material is based on the work functions of both materials.
} 


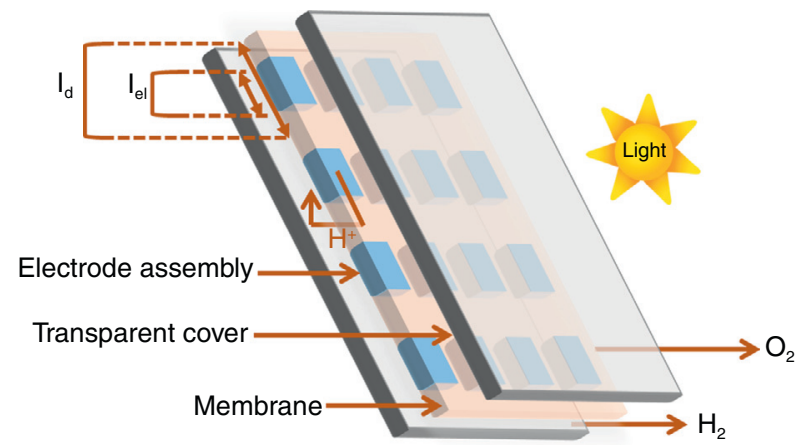

Figure 12

Separator embedded electrode assembly which combines a wireless PEC cell assembly with short ionic pathways.

Additionally, the contact must be protected from the electrolyte and the oxidative impact of the environment. Like in the PV manufacturing and scale up, there will be a trade-off between shading effects and ohmic losses, and a small detrimental effect on overall efficiency cannot be avoided. The use of Transparent Conductive Oxides (TCO) can minimize active surface area losses at the expense of the introduction of larger ohmic losses by the electron transport as TCO show typically larger resistances compared to metals. This disadvantage is slightly reduced by the fact that a smaller current density is experienced in the TCO compared to the metallic current collector due to the larger area available for electron transport in the TCO.

For a wireless configuration, the ionic transport and its associated losses are dominating (Newman, 2013). Here, the electrical contact is made within the SEA and the need for complex contact methods is absent. However, as most efficient PEC cells use dense silicon technology, an ionic transportation problem arises. As the PEC cell surface area increases, ionic transport distance around the SEA increases accordingly (Haussener et al., 2012). In proposed large PEC cell designs, these ohmic losses due to long ion transportation distances are neglected. For devices exceeding centimeter scale dimensions, overpotentials increase significantly with size and will eventually hinder the system operation when not enough driving potential is delivered by the SEA. This problem is gaining awareness and could possibly be overcome by embedding the assemblies as an array inside a membrane as depicted in Figure 12. However, from a manufacturing point of view, this would be difficult to produce as the dimensions of this array should be in the $\mathrm{cm}$ - to $\mu \mathrm{m}$ scale. It is currently unknown if it would be technically and economically possible to produce such a device. Either way, it is obvious that for wireless systems there is a tradeoff between the illuminated area and the area required for ionic transport. This trade-off can be characterized by the ratio $f$ :

$$
f=\frac{l_{\mathrm{el}}}{l_{\mathrm{d}}}
$$

representing the ratio between the electrode length, $l_{\mathrm{el}}$, and the illuminated device length, $l_{\mathrm{d}}$ (Fig. 12). $f$ must be close to 1 to maximize the light absorption potential but must preferably not be below 0.9 to avoid large overpotentials due to high ionic current densities (Haussener et al., 2012). Another possible way to alleviate this trade-off is the use of carefully designed membrane-based PEC cells in which the membrane is placed vertically to minimize its share in the aforementioned ratio (Walczak et al., 2015). Another approach is the use of porous assemblies that simultaneously and perpendicular to the surface allow electronic and ionic transport. One example of such a system are the membrane embedded silicon microwires as reported by Spurgeon et al. (2011). Here, silicon microwires with additional co-catalysts significantly increase active surface area and are embedded in a Nafion ${ }^{\circledR}$ membrane for proton transport with an additional layer of PEDOT:PSS ${ }^{(10)}$ for electrical connection between the anodic and cathodic wires.

In fixed panel PEC cells, the SEA ideally will be placed between two plates $\left(\right.$ e.g. Pyrex $\left.{ }^{\circledR}\right)$ that serve as flow plates to provide water flow to the anode and collect hydrogen at the cathode. Single compartment and dual compartment systems have been proposed (Pinaud et al., 2013; Sathre et al., 2014; Zhai et al., 2013). Compared to exPEC cells, the requirements will be less stringent, but cost and energy requirements for production become important issues. The use of expensive quartz glass is no option. Unless needed, no complicated flow designs and expensive fabrication methods should be used in the simplest possible designs.

In single compartment systems, inclination of the panel has been proposed for the separation of hydrogen and oxygen, and inclination simultaneously ensures optimal illumination intensity (Pinaud et al., 2013).

The choice of electrolyte will have a large impact on the final design, practicability, and cost of a PEC cell. To allow sufficient ionic transport when no separators are present, often highly acidic or basic electrolytes are used (Seger and Kamat, 2009; Chen Q. et al., 2013; Currao et al., 2004). These have the disadvantage of being corrosive and expensive which makes them difficult to apply on a large scale as highly resistant reactor materials must be used throughout the system. In this respect, the development of suitable photoactive materials and catalysts, and device designs, that continuously work under neutral $\mathrm{pH}$ conditions is a much investigated aspect of PEC water splitting.

\footnotetext{
10 PEDOT:PSS = Poly(3,4-EthyleneDiOxyThiophene) Polystyrene Sulfonate.
} 


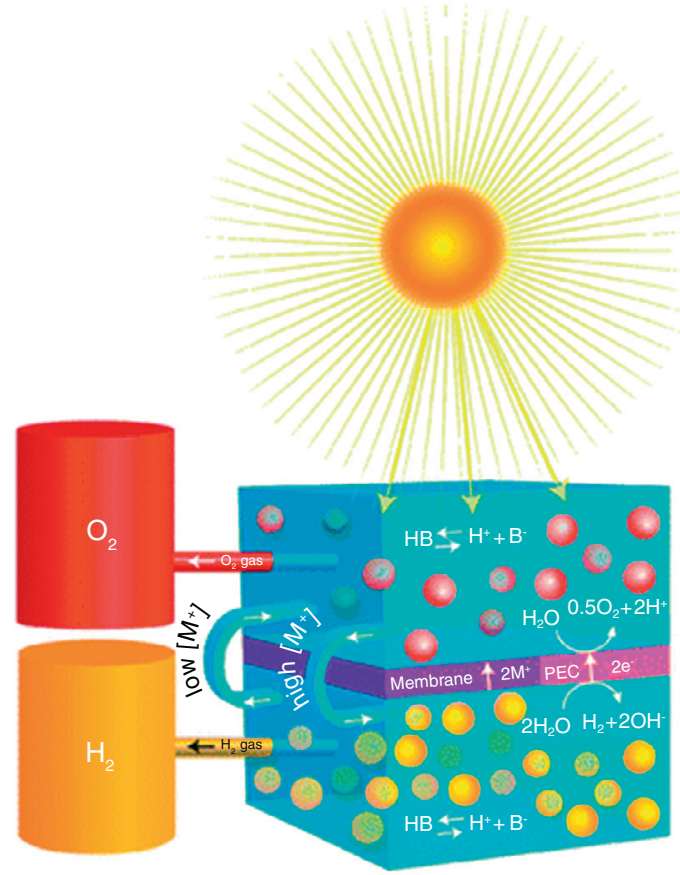

Figure 13

Self-regulating, continuously operating solar fuel generator reported by Modestino et al. (2014).

Additionally, there will be a trade-off concerning the amount of electrolyte inside the PEC cell which needs a certain volume above the electrode to minimize ohmic losses in the solution (Haussener et al., 2012), but must not exceed an upper limit because the added weight and light absorption can become performance limiting factors (Döscher et al., 2014).

However, even when working in concentrated buffered solutions at neutral $\mathrm{pH}$, the formation of a $\mathrm{pH}$ gradient is observed which makes it impossible to keep working in a neutral $\mathrm{pH}$. Additionally, the buffered electrolyte is depleted at the cathode side and a concentration gradient is developed during operation which poses a threat for long term operation of such systems. In the future, adequate membrane materials could allow selective transport of neutral buffer species back to the anode side to alleviate this problem. Here, reactor design can contribute to solutions as well. As reported recently by Modestino et al. (2014), by introducing a controlled recirculating system it is possible to prevent the formation of a significant concentration gradient in buffered near neutral electrolytes, while maintaining sufficient gaseous product separation (Fig. 13). Another option is the use of ambient air as a feedstock. It has been proposed that even in remote, dry areas, air contains enough water to sustain PEC operation. This would make the reactor design a lot easier as water in vapor phase reduces the weight of the PEC cell significantly, is non-corrosive and poses no risk of freezing in winter. However, a cover would still be needed to protect the surface from heavy winds and debris (Rongé et al., 2014a, c).

Concentrating PEC cells, depending on the solar concentration ratio, use between 10 to 1000 times less surface area of the most expensive part of the PEC cell namely the electrode assembly. Here, the ratio $f$ will become even more vital as the small surface area must be used optimally and overpotentials become more severe as the current densities are significantly higher. Concentration PEC cells need to be operated under pressure to take maximum profit from the concentrated electric currents. Concentrator PEC cells have been reported to be technically feasible and economically attractive for large scale hydrogen production. However, publications in literature concerning this technology are scarce (Kelly and Gibson, 2008). Nonetheless, it is certain that multijunction materials will have to be used to maximally take advantage of the solar spectrum and an optimization of bandgap combinations will be needed for maximal efficiency (Haussener et al., 2013). Designing and building the reactor will come at a higher cost as the requirements will be more severe. Elevated temperatures and pressures require more resistant materials both for the electrode assembly as for the reactor, and possibly require an advanced thermal management. Additionally, for wired configurations, electrical contacts will be more resistant (Gessert and Coutts, 1990) and without the use of noble metals, current collection will become problematic as the state-of-the-art reported catalysts for both redox reactions are limited to currents of about $1 \mathrm{~A} . \mathrm{cm}^{-2}$ which would limit the concentration to about 100 suns.

\section{CONCLUSIONS}

An advanced understanding of PEC cell operation is required for practical and large-scale implementation. This understanding can be gained by the design and use of advanced, custom-made experimental PEC cells (exPEC cells). Currently, exPEC cells are mostly single- or dualcompartment cells and are used for evaluation of individual energy materials and their integration in SEA and photoactive assemblies. However, if these systems are to be applied, more insight is to be gained using dual compartments cells with uniform flow patterns and equipped with reference electrodes, and temperature- and $\mathrm{pH}$ sensors as this will reflect more realistic operating conditions. An advanced exPEC cell design meeting these requirements was proposed. Additionally, it is emphasized upscaling of sample fabrication processes plays a crucial role in the applicability of 
large-scale PEC cells. Care must be taken that no other side reactions due to the presence of impurities can occur at the surface caused as this will overestimate the performance. As size increases and samples are often fragile, technical problems arise which have a detrimental effects on the performance of the PEC cell. Large-scale manufacturing of photoactive assemblies such as spatial ALD and inktjet printing have been proposed and these techniques could provide a suitable method for large scale production of PEC cells (Hiller et al., 2002; Poodt et al., 2012).

Wired or small-scale wireless dual-compartment membrane-based flow-type PEC cells are expected to dominate the future PEC market for solar hydrogen production as they provide means for the continuous production and safe separation of hydrogen and oxygen. Therefore a focus on these PEC cells must be put in future research, additionally focusing on scalability in realistic conditions. The potential for concentrated PEC cells for large-scale solar hydrogen production must be investigated as it holds great promise as an alternative for non-concentrated PEC cells which seem to be more suitable for small-scale applications.

\section{ACKNOWLEDGMENTS}

The authors thank Marc Peeters and Joop Vandeurzen for technical drawings and building of the new experimental PEC cell, Philip van Hoof (MSc) for performing PEC experiments and Louis Huguenin (MSc) for performing modeling simulations. The Flemish government is acknowledged for Methusalem long-term structural funding of JAM. JR is grateful to Research Foundation - Flanders (FWO) for a research fellowship.

\section{REFERENCES}

Ampelli C., Centi G., Passalacqua R., Perathoner S. (2010) Synthesis of solar fuels by a novel photoelectrocatalytic approach, Energy \& Environmental Science 3, 3, 253.

Araña J., Doña-Rodríguez J.M., González-Díaz O., Tello Rendón E., Herrera Meliá J.a., Colón G., Navío J.a., Pérez Peña J. (2004) Gas-phase ethanol photocatalytic degradation study with $\mathrm{TiO}_{2}$ doped with $\mathrm{Fe}, \mathrm{Pd}$ and $\mathrm{Cu}$, Journal of Molecular Catalysis A: Chemical 215, 1-2, 153-160.

Chen Q., Li J., Li X., Huang K., Zhou B., Shangguan W. (2013) Self-biasing photoelectrochemical cell for spontaneous overall water splitting under visible-light illumination, ChemSusChem $\mathbf{6}$, 7, 1276-1281.

Chen Z., Jaramillo T.F., Deutsch T.G., Kleiman-Shwarsctein A., Forman A.J., Gaillard N., Garland R., Takanabe K., Heske C., Sunkara M., McFarland E.W., Domen K., Miller E.L., Turner J.a., Dinh H.N. (2011) Accelerating materials development for photoelectrochemical hydrogen production: Standards for methods, definitions, and reporting protocols, Journal of Materials Research 25, 01, 3-16.
Chen Z., Dinh H.N., Miller E. (2013) Photoelectrochemical water splitting Standards, Experimental Methods, and Protocols, Springer, New York.

Conibeer G., Richards B. (2007) A comparison of PV/electrolyser and photoelectrolytic technologies for use in solar to hydrogen energy storage systems, International Journal of Hydrogen Energy 32, 14, 2703-2711.

Currao A., Reddy V.R., van Veen M.K., Schropp R.E.I., Calzaferri G. (2004) Water splitting with silver chloride photoanodes and amorphous silicon solar cells, Photochemical \& Photobiological Sciences: Official Journal of the European Photochemistry Association and the European Society for Photobiology 3, 11-12, 1017-1025.

Döscher H., Geisz J.F., Deutsch T.G., Turner J.A. (2014) Sunlight absorption in water - efficiency and design implications for photoelectrochemical devices, Energy \& Environmental Science 7, 2951-2956.

Gessert T., Coutts T. (1990) Requirements of Electrical Contacts to Photovoltaic Solar Cells, MRS Proceedings.

Hagfeldt A., Lindström H. (1995) Photoelectrochemical studies of colloidal TiO 2 films: The effect of oxygen studied by photocurrent transients, Journal of Electroanalytical Chemistry 381, 39-46.

Haussener S., Xiang C., Spurgeon J.M., Ardo S., Lewis N.S., Weber A.Z. (2012) Modeling, simulation, and design criteria for photoelectrochemical water-splitting systems, Energy \& Environmental Science 5, 12, 9922.

Haussener S., Hu S., Xiang C., Weber A.Z., Lewis N.S. (2013) Simulations of the irradiation and temperature dependence of the efficiency of tandem photoelectrochemical water-splitting systems, Energy \& Environmental Science 6, 12, 3605.

Hernández-Pagán E.a., Vargas-Barbosa N.M., Wang T., Zhao Y., Smotkin E.S., Mallouk T.E. (2012) Resistance and polarization losses in aqueous buffer-membrane electrolytes for water-splitting photoelectrochemical cells, Energy \& Environmental Science 5, 6, 7582.

Hiller J., Mendelsohn J.D., Rubner M.F. (2002) Reversibly erasable nanoporous anti-reflection coatings from polyelectrolyte multilayers, Nature Materials 1, 1, 59-63.

Ichikawa S., Doi R. (1996), Hydrogen production from water and conversion of carbon dioxide to useful chemicals by room temperature photoelectrocatalysis, Catalysis Today 27, 12, 271-277

Jacobsson T.J., Fjällström V., Edoff M., Edvinsson T. (2014) Sustainable Solar Hydrogen Production: From Photoelectrochemical Cells to PV-Electrolysis and Back Again, Energy \& Environmental Science 7, 2056-2070.

James B., Baum G.N., Perez J., Baum K.N. (2009), Technoeconomic analysis of photoelectrochemical (PEC) hydrogen production.

Jin J., Walczak K., Singh M.R., Karp C., Lewis N.S., Xiang C. (2014) An experimental and modeling/simulation-based evaluation of the efficiency and operational performance characteristics of an integrated, membrane-free, neutral $\mathrm{pH}$ solar-driven water-splitting system, Energy \& Environmental Science 7, 10, 3371-3380.

Kelly N., Gibson T. (2006) Design and characterization of a robust photoelectrochemical device to generate hydrogen using solar water splitting, International Journal of Hydrogen Energy 31, 12, 1658-1673.

Kelly N., Gibson T. (2008) Solar energy concentrating reactors for hydrogen production by photoelectrochemical water splitting, International Journal of Hydrogen Energy 33, 22, 6420-6431. 
Lopes T., Andrade L., Ribeiro H.A., Mendes A. (2010) Characterization of photoelectrochemical cells for water splitting by electrochemical impedance spectroscopy, International Journal of Hydrogen Energy 35, 20, 11601-11608.

Lopes T., Dias P., Andrade L., Mendes A. (2014) An innovative photoelectrochemical lab device for solar water splitting, Solar Energy Materials and Solar Cells 128, 399-410.

Mathiesen B., Lund H. (2009) Comparative analyses of seven technologies to facilitate the integration of fluctuating renewable energy sources, IET Renewable Power Generation 3, August 2008, 190-204.

Miller E.L., Rocheleau R.E., Deng X.M. (2003) Design considerations for a hybrid amorphous silicon/photoelectrochemical multijunction cell for hydrogen production, International Journal of Hydrogen Energy 28, 615-623.

Minggu L.J., Wan Daud W.R., Kassim M.B. (2010) An overview of photocells and photoreactors for photoelectrochemical water splitting, International Journal of Hydrogen Energy 35, 11, 5233-5244.

Modestino M.a., Walczak K., Berger A.D., Evans C.M., Haussener S., Koval C., Newman J., Ager J.W., Segalman R.a. (2014) Robust production of purified $\mathrm{H}_{2}$ in a stable, self-regulating, and continuously operating solar fuel generator, Energy \& Environmental Science 7, 1, 297-301.

Newman J. (2013) Scaling with Ohm's Law; Wired vs. Wireless Photoelectrochemical Cells, Journal of the Electrochemical Society 160, 3, F309-F311.

Nielander A.C., Shaner M.R., Papadantonakis K.M., Francis S.a., Lewis N.S., (2014) A taxonomy for solar fuels generators, Energy Environ. Sci. 8, c, 16-25.

Pinaud B.a, Benck J.D., Seitz L.C., Forman A.J., Chen Z., Deutsch T.G., James B.D., Baum K.N., Baum G.N., Ardo S., Wang H., Miller E.L., Jaramillo T.F. (2013) Technical and economic feasibility of centralized facilities for solar hydrogen production via photocatalysis and photoelectrochemistry, Energy \& Environmental Science 6, 7, 1983.

Poodt P., Cameron D.C., Dickey E., George S.M., Kuznetsov V., Parsons G.N., Roozeboom F., Sundaram G., Vermeer A. (2012) Spatial atomic layer deposition: A route towards further industrialization of atomic layer deposition, Journal of Vacuum Science \& Technology A: Vacuum, Surfaces, and Films 30, 1, 010802.

Qian F., Wang G., Li Y. (2010) Solar-driven microbial photoelectrochemical cells with a nanowire photocathode, Nano Letters 10, 11, 4686-4691.

Reece S., Hamel J., Sung K., Jarvi T., Esswein A.J., Pijpers J.J.H., Nocera D.G. (2011) Wireless solar water splitting using siliconbased semiconductors and earth-abundant catalysts, Science 334, 645-648.

Rocheleau R.E., Miller E.L., Misra A. (1998) High-efficiency photoelectrochemical hydrogen production using multijunction amorphous silicon photoelectrodes, Energy \& Fuels 12, 1, 3-10.
Rongé J., Nijs D., Kerkhofs S., Masschaele K., Martens J. (2013) Chronoamperometric study of membrane electrode assembly operation in continuous flow photoelectrochemical water splitting, Physical Chemistry Chemical Physics 15, 23, 9315-9325.

Rongé J., Bosserez T., Huguenin L., Dumortier M., Haussener S., Martens J. (2014a) Solar hydrogen reaching maturity, OGST Revue d'IFP Energies Nouvelles (this issue). DOI: 10.2516/ogst/ 201406.

Rongé J., Bosserez T., Martel D., Nervi C., Boarino L., Taulelle F., Decher G., Bordiga S., Martens J.a. (2014b) Monolithic cells for solar fuels, Chemical Society Reviews 43, 7963-7981.

Rongé J., Deng S., Pulinthanathu Sree S., Bosserez T., Verbruggen S.W., Kumar Singh N., Dendooven J., Roeffaers M.B.J., Taulelle F., De Volder M., Detavernier C., Martens J.A. (2014c) Air-based photoelectrochemical cell capturing water molecules from ambient air for hydrogen production, RSC Advances 4, 55, 29286-29290.

Sathre R., Scown C.D., Morrow W.R., Stevens J.C., Sharp I.D., Ager J.W., Walczak K., Houle F.a., Greenblatt J.B. (2014) Lifecycle net energy assessment of large-scale hydrogen production via photoelectrochemical water splitting, Energy \& Environmental Science 7, 10, 3264-3278.

Schröder V., Emonts B., Janßen H., Schulze H.P. (2004) Explosion Limits of Hydrogen/Oxygen Mixtures at Initial Pressures up to 200 bar, Chemical Engineering \& Technology 27, 8, 847-851.

Seger B., Kamat P. (2009) Fuel cell geared in reverse: photocatalytic hydrogen production using a TiO2/Nafion/Pt membrane assembly with no applied bias, The Journal of Physical Chemistry C 113, 43, 18946-18952.

Spurgeon J.M., Walter M.G., Zhou J., Kohl P. a., Lewis N.S. (2011) Electrical conductivity, ionic conductivity, optical absorption, and gas separation properties of ionically conductive polymer membranes embedded with Si microwire arrays, Energy \& Environmental Science 4, 5, 1772-1780.

van de Krol R., Grätzel M. (2012) Photoelectrochemical hydrogen production, Springer, New York.

Walczak K., Chen Y., Karp C., Beeman J.W., Shaner M., Spurgeon J., Sharp I.D., Amashukeli X., West W., Jin J., Lewis N.S., Xiang C. (2015) Modeling, Simulation, and Fabrication of a Fully Integrated, Acid-stable, Scalable Solar-Driven Water-Splitting System, Chem-SusChem 8, 3, 544-551.

Zhai P., Haussener S., Ager J., Sathre R., Walczak K., Greenblatt J., McKone T. (2013) Net primary energy balance of a solar-driven photoelectrochemical water-splitting device, Energy \& Environmental Science 6, 8, 2380.

\author{
Manuscript submitted in January 2015 \\ Manuscript accepted in April 2015 \\ Published online in August 2015
}

